Article

\title{
In Vivo Analysis of miR-34a Regulated Glucose Metabolism Related Genes in Megalobrama amblycephala
}

\author{
Ling-Hong Miao ${ }^{1} \mathbb{D}$, Yan Lin ${ }^{1}$, Xin Huang ${ }^{2}$, Wen-Jing Pan ${ }^{2}$, Qun-Lan Zhou ${ }^{1}$, Bo Liu ${ }^{1,2}$, \\ Ming-Chun Ren ${ }^{1}$, Xian-Ping Ge ${ }^{1,2, *}$ and Liang-Kun Pan ${ }^{1}$ \\ 1 Key Laboratory of Freshwater Fisheries and Germplasm Resources Utilization, Ministry of Agriculture, \\ Freshwater Fisheries Research Center, Chinese Academy of Fishery Sciences, Wuxi 214081, China; \\ miaolh@ffrc.cn (L.-H.M.); liny@ffrc.cn (Y.L.); zhouql@ffrc.cn (Q.-L.Z.); liub@ffrc.cn (B.L.); \\ renmc@ffrc.cn (M.-C.R.); panlk@ffrc.cn (L.-K.P.) \\ 2 Wuxi Fisheries College, Nanjing Agricultural University, Wuxi 214081, China; \\ 17798746965@163.com (X.H.); pan787856_wj@163.com (W.-J.P.) \\ * Correspondence: gexp@ffrc.cn; Tel.: +86-510-8555-7892; Fax: +86-510-8555-3304
}

Received: 17 July 2018; Accepted: 8 August 2018; Published: 16 August 2018

\begin{abstract}
The Megalobrama amblycephala (M. amblycephala) is one of the most important economic freshwater fish in China. The molecular mechanism under the glucose intolerance responses which affects the growth performance and feed utilization is still confused. miR-34a was reported as a key regulator in the glucose metabolism, but how did the miR-34a exert its function in the metabolism of glucose/insulin in M. amblycephala was still unclear. In this study, we intraperitoneally injected the miR-34a inhibitor ( $80 \mathrm{nmol} / 100 \mathrm{~g}$ body weight) into M. amblycephala (fed with high starch diet, $45 \%$ starch) for $12 \mathrm{~h}$, and then analyzed the gene expression profiling in livers by RNA-seq. The results showed that miR-34a expression in M. amblycephala livers was inhibited by injection of miR-34a inhibitor, and a total of 2212 differentially expressed genes (DEGs) were dysregulated (including 1183 up- and 1029 downregulated DEGs). Function enrichment analysis of DEGs showed that most of them were enriched in the peroxisome proliferator-activated receptor $(P P A R)$, insulin, AMP-activated protein kinase (AMPK) and janus kinase/signal transducers and activators of transcription (JAK/STAT) signaling pathways, which were all associated with the glucose/lipid metabolic and biosynthetic processes. In addition, we examined and verified the differential expression levels of some genes involved in AMPK signaling pathway by qRT-PCR. These results demonstrated that the inhibition of miR-34a might regulate glucose metabolism in M. amblycephala through downstream target genes.
\end{abstract}

Keywords: Megalobrama amblycephala; miR-34a; inhibition; glucose metabolism; RNA-seq

\section{Introduction}

Carbohydrates are the main source of energy in most animal diets [1], and its properties such as digestion and absorption rate, viscosity, structural features, water-binding capacity and fermentation ability in the gastrointestinal tract are of critical importance in the effect of nutrition [2]. It has been reported that the utilization of dietary carbohydrates and their effects on growth and nutrient deposition are very important [3], and the dietary carbohydrate inclusion in several fish species appears to produce positive effects on growth and digestibility [4-6].

Blunt snout bream (Megalobrama amblycephala, M. amblycephala) is one of the most important economic freshwater fish in China [7]. According to the latest statistics from Food and Agriculture Organization (FAO), the total output of M. amblycephala reached nearly 850 thousand tons in 2016, 
and the market demand is increasing due to its high economic value. M. amblycephala is typical herbivorous feeding habit [8], and its digestive function and disease resistance ability are related to high-fat and -glucose diets [9]. Researches have shown that higher carbohydrate dietary formula $(>34 \%)$ might result into glucose intolerance responses in M. amblycephala [10-12]. But the underlying molecular mechanism is still unclear. Our previous study provided a miRNA profiling in response to high starch treatment in M. amblycephala, and showed that miRNAs might play crucial roles in glucose metabolism [9]. In that study, 124 differentially expressed miRNAs (DEMs) were identified in liver tissue between fishes fed with normal and high starch diets and a noteworthy upregulated miRNA, miR-34a, was found in the DEMs list [9]. There might be association between miR-34a upregulation and glucose metabolism.

miR-34a, a highly conserved, endogenous, small non-coding RNA, has emerged as a key biomarker in cellular senescence and tumor suppression through its interaction with SIRT1 (Sirtuin 1) and $p 53$ (Tumor protein p53) [13,14]. miR-34a has additionally been implicated in diabetes as a target to prevent pancreatic $\beta$-cell death $[15,16]$. Several studies had reported that miR-34a was dysregulated in metabolic tissues in rodent models and human patients of obesity, type 2 diabetes (T2D) and Non-Alcoholic Fatty Liver Disease (NAFLD) [17-21]. MiR-34a was highly elevated in liver in NAFLD and T2D patients compared to healthy controls [20,21]. Previous studies suggested that miR-34a regulated fat metabolism and insulin secretion by targeting SIRT1 and acyl-CoA synthetase long-chain family member 1 (ACSL1) $[15,22,23]$. SIRT1 is a key metabolic sensor and regulator in cells and directly deacetylates and modulates some important metabolic regulators, including $P G C-1 \alpha$ (peroxisome proliferator-activated receptor $\gamma$ coactivator 1- $\alpha$ ), peroxisome proliferator-activated receptors (PPARs), $p 53$, and forkhead box protein O1 (FOXO1) which change the expression of transcriptional programs that modulate cholesterol, lipid and energy homeostasis [24]. Moreover, researchers demonstrated that miR-34a was involved in insulin hyposecretion, insulin resistance, and cell injury in a mammalian T2D model [25]. Therefore, we hypothesized that miR-34a might play an important role in promoting glucose intolerance in human and animals.

Researches on the dysregulation of miR-34a in glucose metabolism have been widely reported in rodents and human [26,27], but little is known in the teleosts yet, especially in M. amblycephala. Hence, we used next-generation sequencing technologies to identify the potential regulatory networks of miR-34a in M. amblycephala. In this study, we conducted an in vivo experiment by injecting the inhibitor of miR-34a into M. amblycephala, and then constructed three poly (A) libraries from livers in consideration of the suggestion that the main target organ of miR-34a was liver tissue [28]. After sequencing and bioinformatics analysis, a number of differentially expressed genes (DEGs) including the target genes of miR-34a would be identified. These results may provide new insights into the regulatory mechanism of miR-34a in high-glucose metabolism in M. amblycephala.

\section{Results}

\subsection{Transcriptome Sequencing in M. amblycephala}

Our results suggested that the injection of miR-34a inhibitor ( $80 \mathrm{nmol} / 100 \mathrm{~g}$ body weight) for 12 , 24 , and $48 \mathrm{~h}$ showed significant effect on miR-34a expression level in livers of fishes treated with high starch diet (HSD, $45 \%$ wheat starch, Figure $1, p<0.001$ ). So we performed RNA-seq analysis using the liver samples from fishes treated with antagomiR-34a for $12 \mathrm{~h}$. Three poly(A) ${ }^{+}$RNA-seq libraries were constructed and sequenced using paired-end (PE $2 \times 150)$ Illumina technique. We obtained total 145.5 million pair-end (PE) reads (raw data) from three libraries (Table 1), and 143.6 million reads (clean data) were remained after the removal of ambiguous nucleotides and low-quality sequences, and all the further analyses were performed based on the clean data. RNA-seq data generated in this study had been deposited in the NCBI SRA database (SRP110655). 


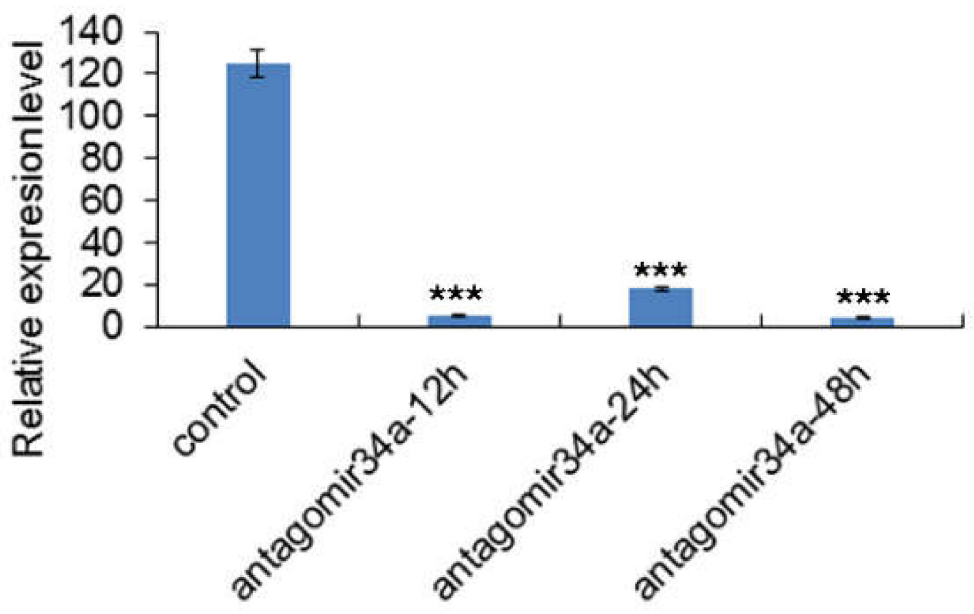

Figure 1. The relative expression level of miR-34a in livers of fishes treated with high starch diet. All fishes were treated with $80 \mathrm{nmol} / 100 \mathrm{~g}$ body weight miR-34a inhibitors (antagomiR-34a) for 12, 24, and $48 \mathrm{~h}$, combined with high starch diet (45\% wheat starch). Relative expression levels of miR-34a was detected using qRT-PCR. ${ }^{* *}$ notes $p<0.001$ vs. control.

Table 1. Summary of the sequencing data from M. amblycephala.

\begin{tabular}{cccccc}
\hline Sample & Raw Reads & Clean Reads & Clean Q20 (\%) & Clean Q30 (\%) & Clean GC (\%) \\
\hline AntagomiR34a-12h & $40,929,414$ & $40,359,036$ & 97.33 & 92.81 & 46.96 \\
Control-1 & $51,674,516$ & $50,991,682$ & 97.39 & 92.97 & 46.35 \\
Control-2 & $52,931,508$ & $52,218,818$ & 97.47 & 93.14 & 47.20 \\
\hline
\end{tabular}

Note: AntagomiR34a-12h: miR-34a knocked down for $12 \mathrm{~h}$ sample, control-1 and control-2 were high-starch samples.

\subsection{De Novo Assembly of the M. amblycephala Transcriptome}

After quality control process, de novo assembly for clean short reads generated from all samples was accomplished by Trinity software with default parameters. Trinity produced 222,411 contigs, corresponding to 197,425 unique genes, with ranged length from 200 to 16,839 bp and N50 of 1041 (Table 2). Length distribution analysis displayed that most contigs were in the range of 200-1000 bp, and only $14.78 \%(32,879)$ contigs ranged from 1000 to 16,839 bp (Figure S1).

Table 2. Overall assembly statistics for the transcriptome of M. amblycephala.

\begin{tabular}{cc}
\hline Item & Value \\
\hline Total number of sequences & 222,411 \\
Total number of genes & 197,425 \\
Total length of sequences $(\mathrm{bp})$ & $151,079,306$ \\
Maximum sequence length $(\mathrm{bp})$ & 16,839 \\
Minimum sequence length $(\mathrm{bp})$ & 200 \\
N50 & 1041 \\
\hline
\end{tabular}

\subsection{Functional Annotation}

To annotate the M. amblycephala transcriptome and identify genes, we performed a functional annotation on the assembly using BLASTx alignment with a cut-off $e$-value $<1 \times 10^{-10}$. All assembled contigs were searched against the $\mathrm{Nr}$ database, UniProt-SwissProt database, COG (Cluster of Orthologous Groups of protein) database, the KEGG (Kyoto Encyclopedia of Genes and Genomes), and Protein Family (Pfam) conserved domain database, respectively. A total of 83,587 cumulatively assembled contigs, corresponding to the prediction of 67,604 unique genes (Table 3), were identified. 
There were 82,223 assembled contigs with significant hits against $\mathrm{Nr}$ database and $87.33 \%$ contigs with an $e$-value of $<1 \times 10^{-10}$ (Figure S2). Most of the annotated contigs were homologous to the Danio rerio (55.85\%) (Figure 2), followed by Astyanax mexicanus (3.73\%) and Chrysemys picta bellii (2.48\%). Moreover, $62.42 \%$ of the assembly contigs could not map to any known proteins. We speculated that some of these sequences were M. amblycephala lineage-specific genes or non-coding RNAs and assembly noises.

Table 3. Statistics of function annotation.

\begin{tabular}{ccc}
\hline Annotated Database & Annotated Number & Transcript Ratio (\%) \\
\hline All_Assembly_Contig & 222,411 & 100 \\
\hline Nr & 82,223 & 36.97 \\
SwissProt & 57,581 & 25.89 \\
KEGG & 71,045 & 31.94 \\
KOG & 45,994 & 20.68 \\
Pfam & 27,677 & 12.44 \\
GO & 25,433 & 11.44 \\
All_anno_contig & 83,587 & 37.58 \\
\hline
\end{tabular}

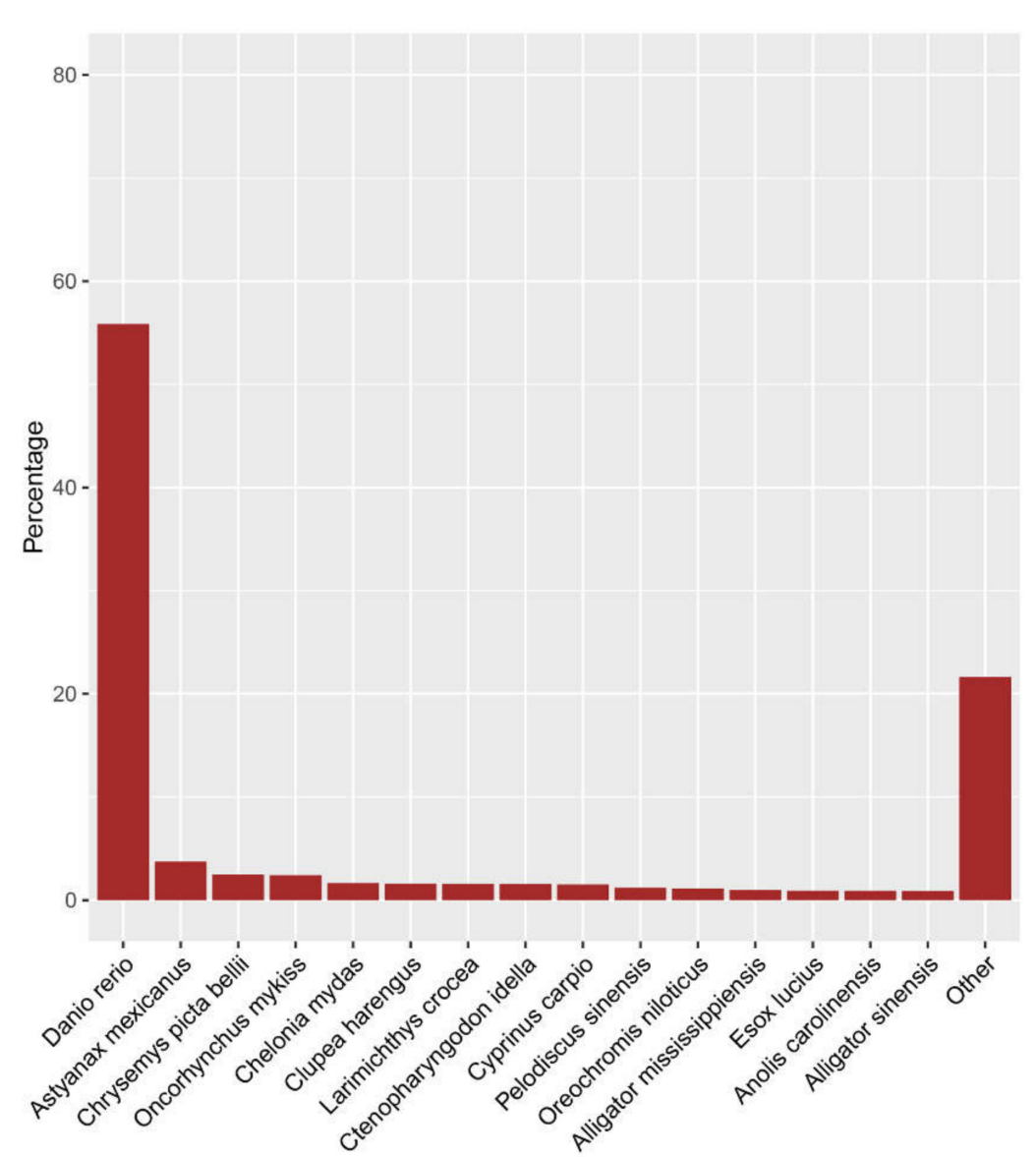

Figure 2. Homologous species distribution of the annotated contigs.

The KEGG analysis helps us to understand the network of molecular interactions in cells in M. amblycephala. Based on the comparison against the KEGG database, 71,045 contigs were annotated and enriched into 322 KEGG pathways, including phosphatidylinositol3-kinase/protein kinase B (PI3K-Akt), MAPK, and insulin signaling pathways (Table S1).

Gene ontology (GO) annotation was then performed based on the $\mathrm{Nr}$ annotation and 25,433 contigs (11.44\%) were assigned to $52 \mathrm{GO}$ terms, including 22 biological process terms, 18 cellular 
component terms and 12 molecular function terms. In the biological process category, cellular process (11,164 genes) was the most abundant term, followed by single-organism process term (10,652 genes) and metabolic process term (8833 genes). For the cellular component category, cell and cell part terms enriched 8274 unigenes. Within the molecular function category, binding $(10,508$ genes) was the most predominant term (Table S1 and Figure S3).

With the COG annotation, the 45,994 contigs were annotated to the 25 COG function clusters (Table S1 and Figure S4). Among the functional classes, the largest cluster was the general function prediction only $(19.77 \%)$, followed by signal transduction mechanisms $(15.77 \%)$, posttranslational modification, protein turnover, chaperones $(9.7 \%)$. Only a few contigs were assigned to cell motility and nuclear structure (Table S1 and Figure S4).

\subsection{Identification of Simple Sequence Repeat}

Simple sequence repeat (SSR) markers are locus-specific, tandem, abundant and highly polymorphic in genome and have been proven to enable the development of molecular markers in genetics and breeding. To discover the SSRs markers in the contigs of M. amblycephala in our study, assembled contigs were used to identify potential microsatellite motifs using MIcroSAtellite (MISA) software. A total of 92,834 SSRs were identified in 61,845 contigs and 20,733 contigs $(33.52 \%)$ having more than one SSR (Table 4 and Table S2). It means that there is a SSR marker per $1.6 \mathrm{~kb}$ in the $M$. amblycephala transcriptome. With the assuming that mononucleotide repeats may be caused by the sequencing errors and assembly mistakes, we excluded 62,185 detected mono-nucleotide repeats. Accordingly, the most abundant type of repeat motifs was dinucleotide (22.02\%), followed by trinucleotide $(8.10 \%)$, tetranucleotide $(2.42 \%)$, pentanucleotide $(0.44 \%)$ and hexanucleotide $(0.04 \%)$ repeats. Future research direction is to discover reliable markers in M. amblycephala. The more information of the SSR was in the Table S2.

Table 4. Distribution of simple sequence repeat (SSR)s based on the number of repeat units.

\begin{tabular}{|c|c|c|c|c|c|c|c|}
\hline \multirow{2}{*}{ Repeat Numbers } & \multicolumn{6}{|c|}{ SSR Type } & \multirow{2}{*}{ Total } \\
\hline & Mono- & Di- & Tri- & Tetra- & Penta- & Hexa- & \\
\hline 5 & 0 & 0 & 3436 & 996 & 154 & 21 & 4607 \\
\hline 6 & 0 & 4847 & 1545 & 710 & 38 & 11 & 7151 \\
\hline 7 & 0 & 2673 & 948 & 75 & 18 & 1 & 3715 \\
\hline 8 & 0 & 1674 & 873 & 93 & 24 & 1 & 2665 \\
\hline 9 & 0 & 1266 & 134 & 60 & 35 & 0 & 1495 \\
\hline 10 & 11,710 & 1138 & 198 & 60 & 22 & 1 & 13,129 \\
\hline 11 & 7843 & 2036 & 129 & 38 & 24 & 0 & 10,070 \\
\hline 12 & 5217 & 1165 & 84 & 27 & 27 & 0 & 6520 \\
\hline$\geq 13$ & 37,415 & 5640 & 172 & 190 & 64 & 1 & 43,482 \\
\hline Total & 62,185 & 20,439 & 7519 & 2249 & 406 & 36 & 92,834 \\
\hline$\%$ & $66.99 \%$ & $22.02 \%$ & $8.10 \%$ & $2.42 \%$ & $0.44 \%$ & $0.04 \%$ & \\
\hline
\end{tabular}

\subsection{Open Reading Frame Identification and Prediction}

For the assembled contigs which had hits against $\mathrm{Nr}$ database, there were 75,338 annotated contigs were found containing the ORF (Open Reading Frame), with a range of 102-13,158 bp and an average of $646.79 \mathrm{bp}$ (Figure 3A). The Transdecoder program was performed to detect the potential ORF regions in the remaining unannotated contigs. Results showed that there were 3245 contigs containing predicted ORF region, with an average, minimum, and maximum length of 394.29, 297 and $5737 \mathrm{bp}$, respectively (Figure 3B). There were 143,828 contigs containing no ORF regions, which suggested that they might come from non-coding genes or uncompleted assembled untranslated regions (UTR). 


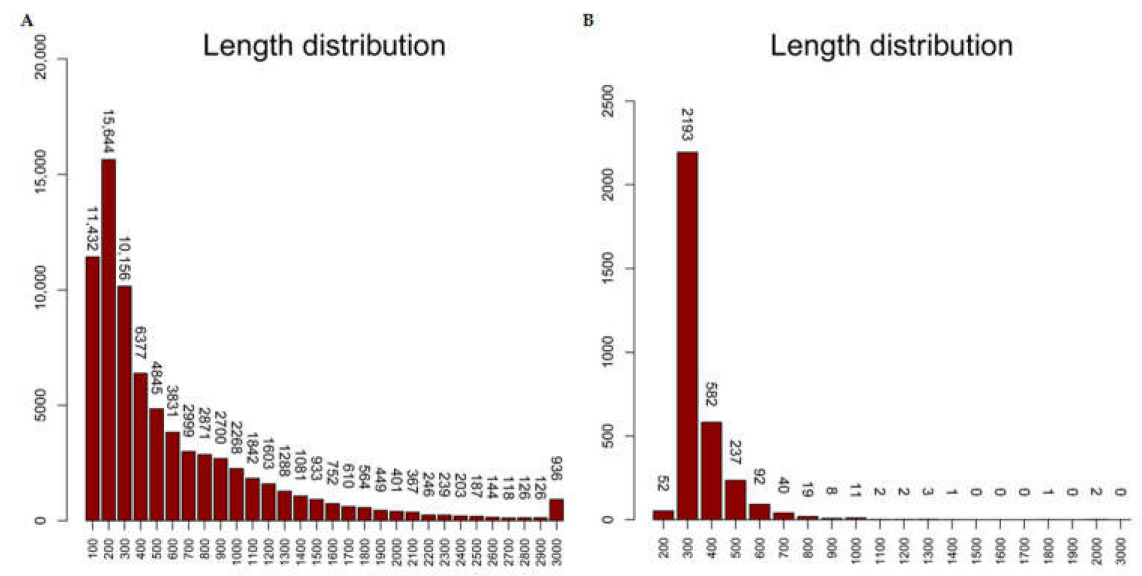

Figure 3. Open reading frame (ORF) length distribution of the annotated contigs (A) and the predicted ORF length distribution of the unannotated contigs (B) in M. amblycephala.

\subsection{DEG Predication and Clustering Analysis}

With the criteria of $\mid$ LogFC (Fold change) $\mid \geq 1$ and FDR (False Discovery Rate) $\leq 0.05$, we identified 2212 DEGs, including 1183 (53.55\%) upregulated DEGs and 1029 (46.45\%) downregulated DEGs, in antagomiR34a-12h samples comparing with the control (Figure 4). In the list of all DEGs, we found that PIK3R1 (phosphatidylinositol 3-kinase regulatory subunit $\alpha$ ), PEPCK (phosphoenolpyruvate carboxykinase), IL6RA (interleukin-6 receptor subunit $\alpha$ ), INSIG1 (insulin-induced gene 1 protein), MHCI (major histocompatibility complex class I), MHCII (major histocompatibility complex class II), GADD45B (Growth arrest and DNA-damage-inducible, $\beta$ ), CES1 (Carboxylesterase 2), HDAC10 (Histone deacetylase 10), ACC1 (acetyl-CoA carboxylase 1), CREBBP (CREB-binding protein isoform X3), PGC-1 $\alpha$ (peroxisome proliferator-activated receptor $\gamma$ coactivator 1- $\alpha$ ), and HMGCR (3-hydroxy-3-methylglutaryl-coenzyme A reductase) were dysregulated in the antagomiR34a-12h samples comparing with control (Table S3). All these genes were directly or indirectly responded to glucose and insulin metabolism [24]. Hierarchical clustering and heat mapping of the DEGs indicated the different expression profiles of all DEGs in livers between control and antagomiR34a-12h group (see Figure S5).

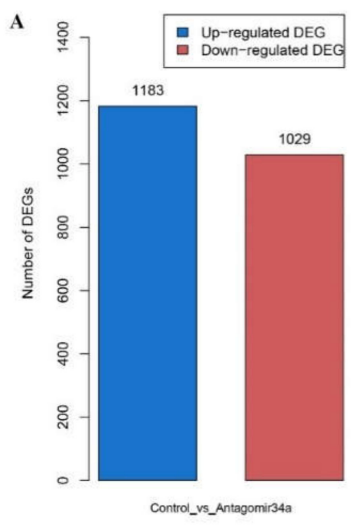

B

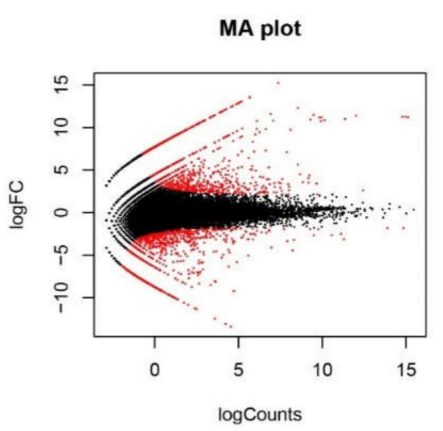

Figure 4. Differentially expressed genes in M. amblycephala in response to miR-34a inhibitor treatment. (A) Blue represents upregulated genes and red represents the downregulated genes in antagomiR34a-12h group vs. control group. $\mid \log 2 \mathrm{FC}($ Fold change) $\mid \geq 1$ and $p$-value $\leq 0.05$; (B) MA plot of all DEGs, the $y$-axis represents the logarithm of fold change and the $x$-axis represents the logarithm of read counts. Red color represents DEGs and black color represents non-DEGs. 
To validate the reliability of RNA-seq in this study, the expression level of 15 glucose metabolic-related genes were analyzed by qRT-PCR. As shown in Figure 5, the qRT-PCR results were in high accordance with the RNA-seq analysis. All genes were in consistent with the RNA-seq results. The results showed that the expression patterns of these genes were in consistent in two methods, which was helpful for confirming the validity of our analysis of glucose metabolism in M. amblycephala.

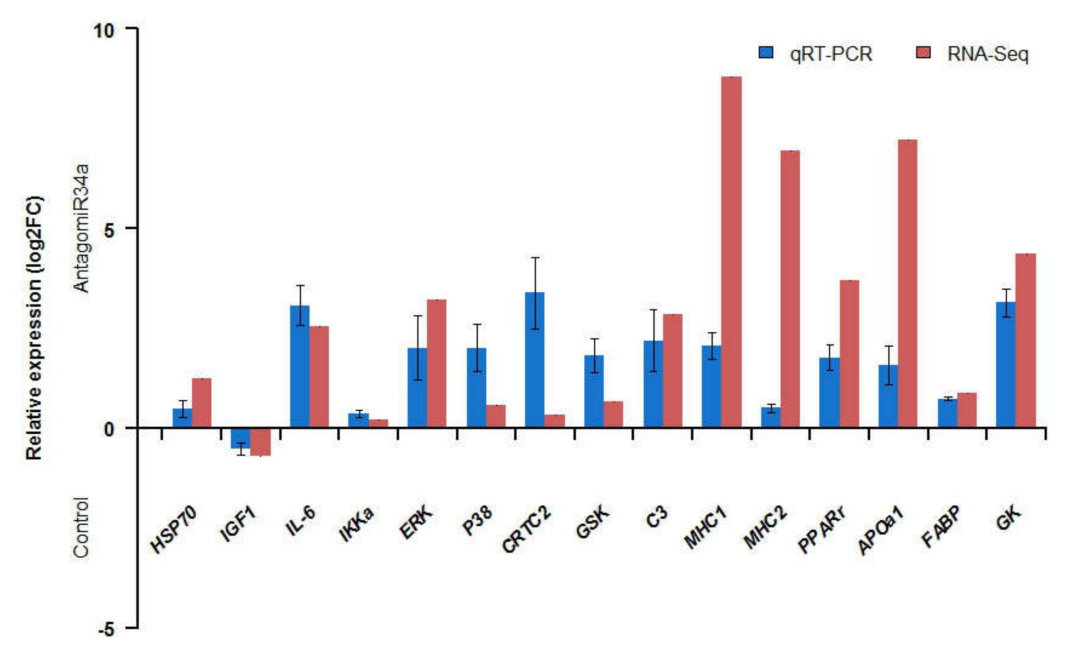

Figure 5. Gene expression patterns of RNA-Seq and qRT-PCR. $\beta$-actin was used as an internal control and used for the normalization of the expression level of each gene. Log-fold changes are expressed as the ratio of gene expression. Error bars represent standard error.

\subsection{Gene Ontology (GO) and Kyoto Encyclopedia of Genes and Genomes (KEGG) Pathways Enrichment} Analysis of differentially expressed genes (DEGs)

In order to obtain the potential function annotation of all DEGs, further enrichment analysis of the GO terms and KEGG pathways were performed (Figures 6 and 7, and Table S4). Based on the GO functional annotation, we found DEGs were classified into decades of molecular functions, cellular components and biological processes (corrected $p<0.05$, Figure 6 and Table S4), including somelipid, glucose, insulin metabolic-related terms (i.e., lipid metabolic process (GO:0006629), cholesterol metabolic process (GO:0008203), glucose metabolic process (GO:0006006), response to lipid (GO:0033993), carboxylic acid metabolic process (GO:0019752) and carboxylic acid transport (GO:0046942)). For example, some genes including downregulated PEPCK, PKM (pyruvate kinase PKM-like), and INSIG1 were enriched into these GO terms.

KEGG pathway enrichment analysis showed that the most significant enriched signal pathway was JAK-STAT signaling pathway (ko04630) (Figure 7 and Table S4). It has been reported that the JAK-STAT pathway was responded to the metabolism in both type 1 diabetes (T1D) and T2D [29]. Obesity is a major risk factor for development of T2D, and lacking of leptin or the leptin receptor $(L e p R b / O b R b)$ will develop severe obesity and insulin resistance. When leptin binds to the $\beta$-isoform of the leptin receptor, JAK2 is activated by autophosphorylation to phosphorylate tyrosine residues on the cytoplasmic tail of the receptor [30]. The enriched DEGs, such as STAT1 (signal transducer and activator of transcription 1), were upregulated and the leptin was downregulated in antagomiR34a-12h samples, which was in coincidence with the former research $[29,30]$. In addition, we found some notable pathways, including type I diabetes mellitus (ko04940), type II diabetes mellitus (ko04930), PPAR signaling pathway (ko03320), fatty acid biosynthesis (ko00061), fat digestion and absorption (ko04975), p53 signaling pathway (ko04115), insulin signaling pathway (ko04910), PI3K-Akt signaling pathway (ko04151), glycolysis/gluconeogenesis (ko00010) and insulin secretion (ko04911), were associated with these DEGs. DEGS were found to be significantly enriched into glucose/insulin related pathways, 
in which upregulated MHC1 and CREBBP and downregulated MHCII and PIK3R1 serve as key regulatory proteins. For instance, $M H C 1$, a T1D related genes [31], was found upregulated in the antagomiR34a-12h sample.

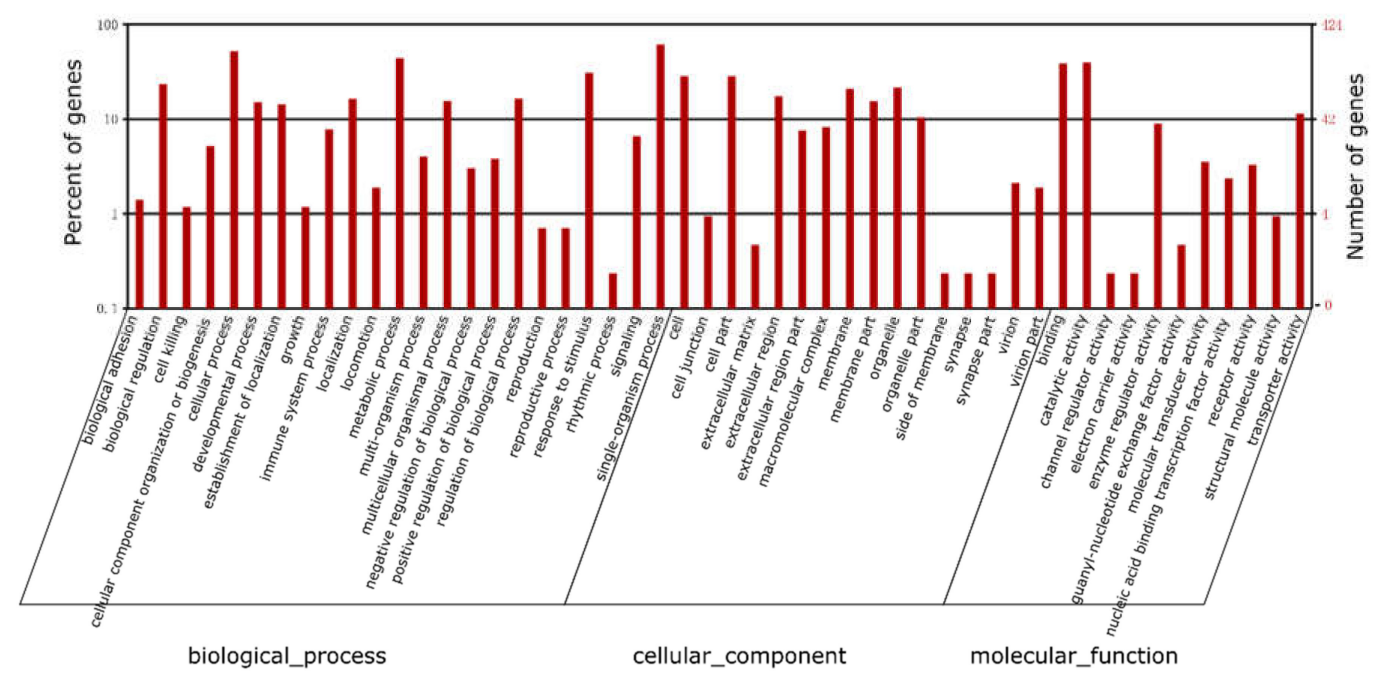

Figure 6. Gene ontology enrichments of all differentially expressed genes responded to miR-34a inhibitor treatment.

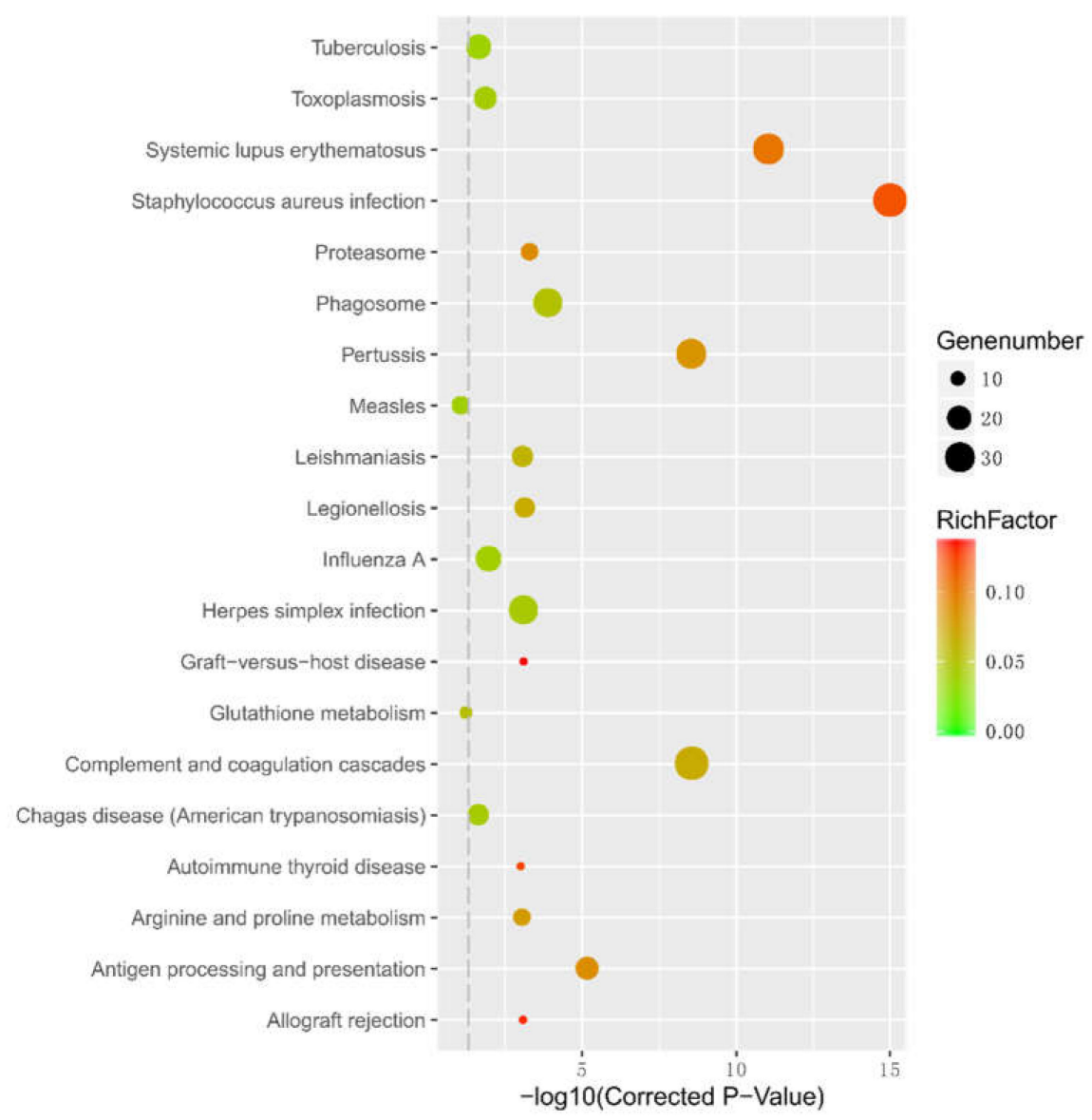

Figure 7. Glucose metabolic-related KEGG pathways for differentially expressed genes responded to miR-34a inhibitor treatment. 


\subsection{Change of Some Other Glucose Metabolism Related Genes after Inhibition of miR-34a}

The RNA-seq results showed that the mRNA levels of some gluconeogenic genes were not significantly differentially expressed, such as $P P A R b$ (Peroxisome proliferator-activated receptor $b$ ), 4EBP2 (Eukaryotic translation initiation factor 4E-binding protein 2), AMPK (AMP-activated protein kinase), STAT1, PKM (pyruvate kinase PKM-like isoform X1), G6Pase (Glucose6-phosphatase), and SCD (Stearoyl-CoA Desaturase). So we carried out additional qRT-PCR analysis to detect their expression levels in livers of M. amblycephala treated with miR-34a inhibitor or control. In addition, we planned to determine if these dysregulations were progressive with treatment time or not. Changes in the relative mRNA levels of these genes were shown in Figure 8. The expression of PPARb, 4EBP2, AMPK, STAT1 and $P K M$ were increased by antagomiR34a treatments comparing with control, and the expression levels of G6Pase and SCD were downregulated in antagomiR34a-12h group in comparison with control. We also found that $3 / 7$ tested genes were increased in liver samples at $24 \mathrm{~h}$ post antagomiR34a treatment comparing with those at $12 \mathrm{~h}$. These might suggested that glucose related genes were progressively accumulated in livers by miR-34a inhibitor injection into M. amblycephala.
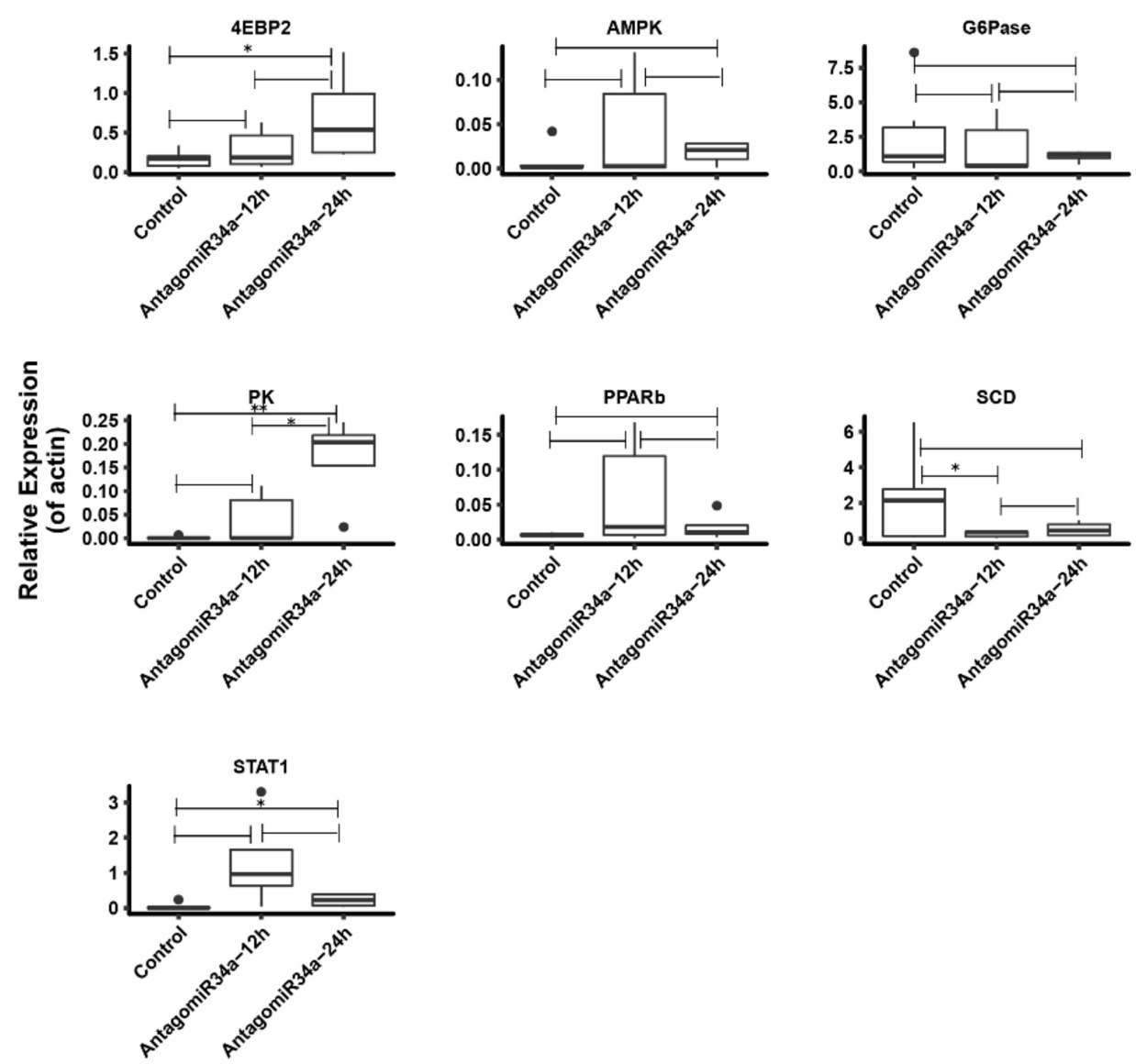

Figure 8. qRT-PCR analysis of some glucose metabolism-related genes involved in AMPK signaling pathway. ${ }^{*} p<0.05 ;{ }^{* *} p<0.01$. Data not included between the whiskers was plotted as an outlier with black dot.

\section{Discussion and Conclusions}

M. amblycephala is a widely cultured freshwater fish in China, but the molecular mechanism of nutritional utilization of dietary carbohydrates is still unclear [32]. Previous studies had demonstrated that altered dietary and metabolic conditions were affected by gene regulation in the cell nucleus [24]. We had previously performed a next-generation sequencing study between normal starch diet and 
high starch diet treated fishes, and identified hundreds of DEMs that responded to HSD treatment in intestine, liver, and brain in M. amblycephala, respectively, suggesting that miRNAs might play crucial roles in glucose metabolism [9]. Among the DEMs, we found that the miR-34a was significantly upregulated in HSD group. miR-34a was a key regulator in the glucose metabolism [17-21], and miR-34a upregulated expression had been identified in T2D patients compared to health controls [21]. A plausible molecular mechanism for the role and function of miR-34a in metabolism was the loop of miR-34a, SIRT1 and p53 [33]. But how miR-34a affected the course of glucose intolerance responses in $M$. amblycephala was still unknown.

So we conducted an in vivo experiment with intraperitoneally injection of miR-34a inhibitor into M. amblycephala, and identified the DEGs related to miR-34a inhibition. The qRT-PCR analysis showed that miR-34a was significant inhibited at 12,24 and $48 \mathrm{~h}$ post the antagomiR34a treatments, with dysregulation of 2212 DEGs. GO and KEGG pathway analysis showed that the DEGs were enriched in the signaling pathways, including PPAR pathway, insulin signaling pathway, JAK/STAT signal pathway, Type I diabetes mellitus and Type II diabetes mellitus, which were associated with glucose/lipid metabolic pathways and biosynthetic processes. All these results implied that the inhibition of miR-34a could regulate a series of genes, which might be crucial for glucose metabolism in M. amblycephala.

Previous studies have demonstrated that miR-34a could reduce the expression level of SIRT1 and prevent the activation of PGC-1 $\alpha, P P A R \alpha, p 53$ and FOXO1 to alter the expression of transcriptional progresses and supervise lipid/glucose, cholesterol and energy homeostasis [34-41]. But the expression levels of these genes were not significantly differentially expressed in our study. We found that one of the PPARs family members, PPARb, was upregulated in antagomiR34a treated samples by qRT-PCR (Figure 8). PPARb was a nuclear hormone receptor which governs a variety of biological processes and may be involved in the development of several diabetes and obesity diseases [42,43]. For example, Sanderson et al., proved that $P P A R b / \delta$ deletion could downregulate the pathways associated with lipoprotetin metabolism and various pathways related to glucose utilization [44]. Consistent with these results, we found $P P A R b$ was upregulated in samples injected with miR-34a inhibitors, implying that the deletion of miR-34a could upregulate $P P A R b$ and the pathways associated with the glucose metabolism in M. amblycephala. These might provide a potential novel role of miR-34a in the regulation of glucose metabolism in M. amblycephala.

In addition to the genes involved in the putative regulatory loop of miR-34a and SIRT1 (Figure 9) [45], other regulators responded to insulin and glucose homeostasis were found dysregulated in the analysis of RNA-seq data. For example, NSIG1, the negative regulator of SREBPs, was downregulated in antagomiR34a-12h sample. Previous study showed that the overexpression of INSIG1 could significantly inhibit SREBP-1c expression and thereby blocking the expression of downstream genes related to insulin and lipid metabolic pathways (Figure 9) [46]. Consistent with this, the downregulated INSIG1 was detected in antagomiR34a-12h sample, which might increase the expression of SREBPs and the downstream genes. We also found that PLCB (phosphatidylinositol phospholipase $C, \beta), G A D D 45 A$ (Growth arrest and DNA-damage-inducible protein GADD45 $\alpha$ ), and $F A B P$ (fatty acid-binding protein) and ACSL1 were downregulated after inhibiting miR-34a in M. amblycephala (Table S3). ACSL1 is one of the long chain acyl-CoA synthetases in lipid metabolism and also been implicated in the cellular uptake of fatty acids. The overexpression of ACSL1 showed increased acyl-CoA synthetase activity and fatty acid uptake [47]. In this study, the ACSL1 was found downregulated in antagomiR34a-12h sample comparing with control. These results implied that the inhibition of miR-34a might play potential novel roles in glucose homeostasis in M. amblycephala by directly or indirectly regulating these key genes.

The DEGs in response to miR-34a inhibition in M. amblycephala livers was associated with JAK/STAT and PPAR signaling pathways. Some not significantly enriched pathways, including insulin-signaling pathway, Type I diabetes mellitus and Type II diabetes mellitus, were also found in the result of KEGG analysis. These pathways were related to DEGs including upregulated PPP1C 
(serine/threonine-protein phosphatase PP1 catalytic subunit) and IL6RA (interleukin 6 receptor $\alpha$, downregulated) and downregulated CNTF (ciliary neurotrophic factor). Elevated IL6 had been reported in diabetes mellitus type 2 [48]. We checked the expression level of IL6 and found that IL6 was upregulated in the antagomiR34a-treated sample (Figure 5). All these results suggested that inhibited miR-34a might regulate the glucose metabolism by altering pathways related to glucose utilization.

To avoid the incomplete results of RNA-seq from being less sequences samples, we carried out an additional qRT-PCR analysis to detect the expression profiles of glucose metabolism related genes. The results showed that the profiles of 7 selected key genes were all as expected and most of these genes were involved in the AMPK signaling pathway (Figures 8 and 9). AMPK is an energy sensor that regulates cellular metabolism which could stimulate glucose uptake to produce energy when activated by a deficit in nutrient status [49]. Evidence has shown that gluconeogenesis in the liver is regulated by multiple enzymes such as PEPCK and G6Pase (Figure 9) [50], and the activation of $A M P K$ could suppress the transcription of G6Pase in hepatoma cells [51]. Andreelli et al., suggested that there was glucose intolerant and fasting hyperglycemia in $A M P K \alpha 2$ liver-specific knockout mice, which presumably due to the increased PEPCK and G6Pase activity [52]. In our study, AMPK was found to be upregulated in the miR-34a inhibitor-injected samples and the expression level of G6Pase was decreased by qRT-PCR analysis (Figure 8). Another gene PPARb was involved in the glucose metabolism by activating a program that increased the coupling of glycolysis to glucose oxidation in muscle via the cooperation with AMPK signaling pathway to activate Ldhb gene transcription [53]. As expected, the relative expression level of $P P A R b$ was found to be increased in the miR-34a-inhibited group by qRT-PCR analysis, which revealed that the knock-down of miR-34a might upregulate $P P A R b$ expression, which then subsequently interacted with $A M P K$ to regulate the glucose metabolism in the liver tissue in M. amblycephala. In addition, the expression level of 3/7 selected AMPK signaling pathway related genes showed a progressively accumulation along with handling time post injection of miR-34a inhibitor (Figure 8). These results implied that miR-34a could interact with AMPK signaling pathway to regulate the glucose embolism in M. amblycephala.

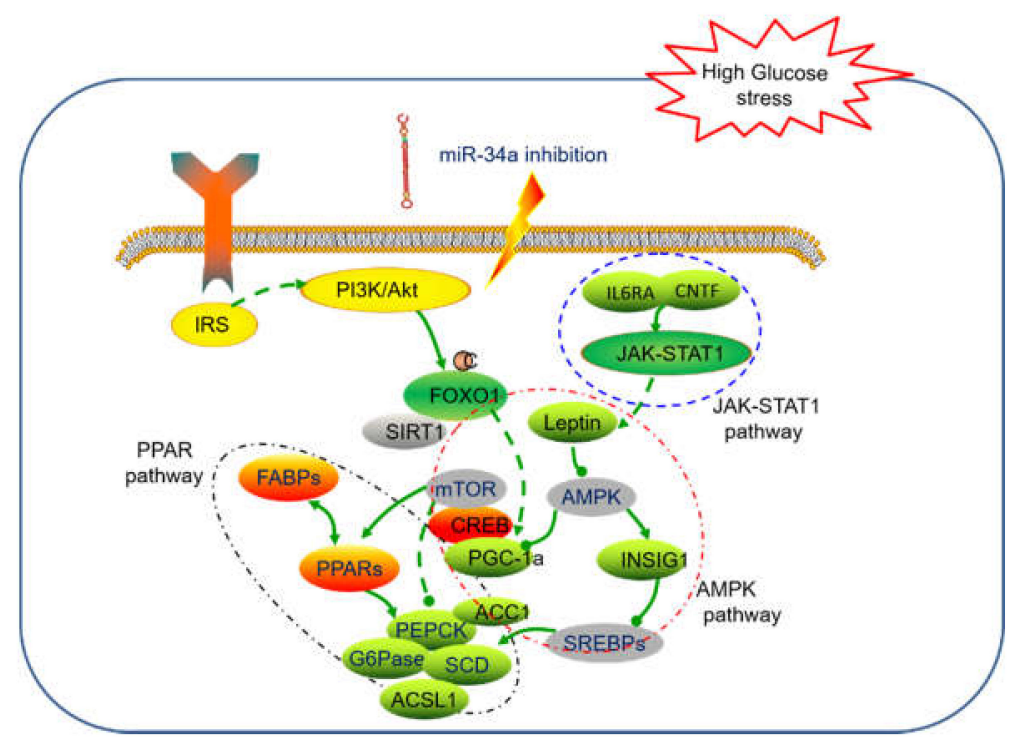

Figure 9. The potential interaction and molecular mechanism of putative genes involved in glucose metabolism process regulated by miR-34a inhibition. Green indicates downregulation, while and red and yellow note upregulation in our study. Gray notes no detection of dysregulation. The blue, red and grey circles include related genes in JAK-STAT1 pathway, AMPK pathway and PPAR pathway, respectively. The green line with an arrow and the green line with a ball stand for positive and negative effect between genes, and the green dot line with an arrow and the green dot line with a ball stand for supposed positive and negative effect between genes. 
All the results in this study showed that the miR-34a was an important regulator in the glucose metabolism by activating or inactivating the downstream genes involved in the glycometabolism. The regulation of the expression level of miR-34a or its targets genes might provide a novel regulatory role in glucose metabolism in M. amblycephala.

\section{Material and Methods}

\subsection{Ethics Statement}

All experimental protocols, methods and feeding scheme were approved on October, 2017 by the Institutional Animal Care and Use Committee of Freshwater Fisheries Research Center, Chinese Academy of Fishery Sciences (Wuxi, China) in this study. All fishes were anesthetized in well-aerated water with 0.01\% tricaine methanesulfonate (MS-222; Sigma, Saint Louis, MO, USA) and sacrificed according to the Guide for the Care and Use of Laboratory Animals of China.

\subsection{Sample Collection}

M. amblycephala were obtained from the Freshwater Fisheries Research Center (FFRC) in Wuxi, Jiangsu province, China. 120 healthy and young fishes (initial weight: $27.54 \pm 0.16 \mathrm{~g}$ ) were maintained in conical fiberglass tanks (volume: $300 \mathrm{~L}$ ) in a flow-through water system (speed: $3 \mathrm{~L} / \mathrm{min}$ ) during the acclimation and experimental period. Water temperature was maintained at $26.0 \pm 1.5^{\circ} \mathrm{C}, \mathrm{pH}$ $=6.8-7.0$, dissolved oxygen $\geq 6 \mathrm{mg} \cdot \mathrm{L}^{-1}$, ammonia nitrogen $\leq 0.2 \mathrm{mg} \cdot \mathrm{L}^{-1}$, nitrite $\leq 0.02 \mathrm{mg} \cdot \mathrm{L}^{-1}$. Aeration was supplied to each tank $24 \mathrm{~h}$ per day and natural photoperiod was followed. All fishes were fed with high starch diet (45\% wheat starch, HSD). The formulation and proximate composition of the HSD were shown in Table 5.

Table 5. Formulation and proximate composition of the HSD (\%).

\begin{tabular}{cccc}
\hline Ingredient & Quantity $\mathbf{( g )}$ & Proximate Composition & (\% of Dry Matter) \\
\hline Casein $^{1}$ & 20 & Crude protein & 33.32 \\
Gelatin $^{\text {Fish meal }}{ }^{2}$ & 5 & Crude lipid & 8.58 \\
Wheat starch $^{3}$ & 16 & Digestible carbohydrate & 45.25 \\
Soybean oil $^{4}$ & 45 & Energy $\left(\mathrm{kJ} \cdot \mathrm{g}^{-1}\right)$ & 18.55 \\
Vitamin additive $^{5}$ & 7 & Calcium & 1.06 \\
Mineral additives $^{5}$ & 1 & Total phosphorus & 1.32 \\
Carboxymethycellulose $^{5}$ & 1 & & \\
Monocalcium phosphate $^{5}$ & 4 & & \\
\hline
\end{tabular}

Note: ${ }^{1}$ Provided by Provided by Feeer Co., Ltd. (Shanghai, China), protein content $88.7 \%{ }^{2}$ Provided by Tongwei Co., Ltd. (Wuxi, China). Protein content $61.2 \% ;{ }^{3}$ Provided by Jinglingta Co., Ltd. (Wuxi, China); ${ }^{4}$ Fat acid content of $0.096 \%$ C $14: 0,11.479 \%$ C16:0, $0.105 \%$ C16:1, 0.095\% C17:0, 4.264\% C18:0, 20.132\% C18:1, 55.706\% C18:2, 7.247\% C18:3n3, 0.319\% C20:0, 0.246\% C20:1 and 0.313\% C22:0; ${ }^{5}$ Provided by Wuxi Hanove Animal Health Products Co., Ltd. (Wuxi, China). Vitamins premix and mineral premix was as referred to Ren et al. [54].

After the preliminary breeding of 8 weeks, 60 fishes were randomly selected for further researches. Thirty fishes were intraperitoneally injected with miR-34a inhibitors (5'ACAACCAGCUAAGACACUGCCA-3', antagomiR-34a; $80 \mathrm{nmol} / 100 \mathrm{~g}$ body weight (RIOBIO, Guangzhou, China), and the other 30 fishes were intraperitoneally injected with miR-34a inhibitor negative control (5'-UGUUGGUCGAUUCUGUGACGGU-3' ', NC; 80 nmol/100 g body weight; RIOBIO, Guangzhou, China) and were set as control group. Nine fishes injected with antagomiR-34a NC and antagomiR-34a at $12 \mathrm{~h}$ (antagomiR-34a-12h), $24 \mathrm{~h}$ (antagomiR-34a-24h) and $48 \mathrm{~h}$ (antagomiR-34a-48h) were collected, respectively, and anaesthetized using MS-222. The liver tissues were stripped immediately, stored at $-80{ }^{\circ} \mathrm{C}$ and prepared for RNA isolation. 


\section{3. $q R T-P C R$ Analysis for the miR-34a}

Total RNA was extracted from M. amblycephala samples using TRizol (Invitrogen, Carlsbad, CA, USA) according to the manufacturer's protocol. RNA purity was assessed using the NanoDrop-2000 (Thermo Fisher Scientific, BRIMS, Cambridge, MA, USA). RNA samples with A260:A280 ratios above 1.9 and A260:A230 ratios above 1.8 were used for reverse transcription with miRNA specific stem-loop primers (Table S5) and the PrimeScript RT Reagent kit (Takara Bio, Dalian, China). QRT-PCR analyses were performed according to methods described by Miao et al. [9]. The relative expression level of the miR-34a was calculated in terms of threshold cycle value $\left(C_{t}\right)$ and normalization to the expression of $5 \mathrm{~S}$ rRNA using the equation $2^{-\Delta \Delta C \mathrm{t}}$, where $\Delta C_{\mathrm{t}}=C_{\mathrm{t} \text { miRNA }}-C_{\mathrm{t} 5 \mathrm{~s}}$.

\section{4. cDNA Library Construction and Sequencing}

Total RNA was extracted as described above. Three samples (control-1, control-2 and antagomiR-34a-12h) with the RNA integrity Number (RIN) larger than 7.0 were selected for transcriptome sequencing. Next, three sequencing libraries were constructed by TruSeq ${ }^{\mathrm{TM}} \mathrm{RNA}$ Sample Preparation Kit according to the product instruction (Illumina, San Diego, CA, USA). Each library was sequenced using Illumina HiSeq 4000 for $2 \times 150 \mathrm{bp}$ pair-end (PE) sequencing.

\subsection{De Novo Assembly of Reference Sequences}

Fastqc (http://www.bioinformatics.babraham.ac.uk/projects/fastqc/) software was used to perform the quality control of all raw reads. In this filtering step, we excluded the poor quality reads, including adaptor reads or unknown base more than $10 \%$ and low-quality reads (reads having more than $50 \%$ bases with quality value $\leq 5$ ). Then the clean reads were firstly de novo assembled into contigs by Trinity software (version trinityrnaseq-2.0.2) with default parameters [55]. Finally, the obtained non-redundancy assembled contigs were clustered using CD-Hit (version v4.6.4) at 90\% similarity and the remaining contigs were used for downstream analysis [56]. The resulting contigs were considered as the M. amblycephala reference sequences.

\subsection{Assembled Sequence Annotation and Classification}

BLASTx(version 2.5.0) alignment with a cut-off $e$-value $<1 \times 10^{-10}$ was performed to search against four public database, including NCBI Nr (Non-redundant protein) database [57], the UniProt-SwissProt (The Universal Protein Resource) database [58], the COG database [59], Pfam database [60] and the KEGG database [61]. The gene name and description of the best blast hit was assigned to each contig.

\subsection{SSRs Identification}

MIcroSAtellite (MISA) (http:/ / pgrc.ipk-gatersleben.de/misa/misa.html) was used to detect the SSR motifs in all assembled contigs with the parameters of at least 6 repeats for di-nucleotide and 5 repeats for tri-, tetra-, penta- and hexa-nucleotide. The compound motifs containing more than one microsatellite sequences separated by 100 bases were also identified.

\subsection{ORF Identification and Prediction}

We used an in-house Perl scripts to obtain the ORF regions within the contigs which had hits against the $\mathrm{Nr}$ database. For the unannotated contigs, we used Transdecoder (http:/ / transdecoder. sourceforge.net/) program to predict the putative ORFs regions. Full-length ORF region were defined as the ORF region of a contig can cover the entire length of the subject protein. As for the other case, the completeness percentage was calculated by the subject protein coverage. 


\subsection{Identification of DEGs}

Bowtie (version 1.0.0) [62] and RSEM (version 1.2.21) [63] program were used to quantify the abundances for all genes and isoforms in two groups. Gene expression was normalized by FPKM (fragments per kilobase of exon per million reads mapped). Then, edgeR (version 3.10.5) [64] was used to identify the DEGs by pairwise comparisons in the control and antagomiR-34a-12h samples. The cut-off criteria for DEGs were $|\log F C| \geq 1$ and FDR $\leq 0.05$ between two groups. GO term annotation was performed using the GO::TermFinder program (version 0.86) to unravel the statistically significant enrichment of DEGs with a correct $p$-value cutoff of 0.05 [65]. KEGG metabolic pathway analysis was conducted using the KOBAS program (version 2.0), taking the correct $p$-value $\leq 0.05$ as a threshold to identify enrichment pathway [66].

\subsection{QRT-PCR Analysis for DEGs}

Total RNA was extracted as described before and the primers of all selected genes were designed (Table S1). qRT-PCR was performed on the ABI PRISM 7500 real-time PCR System (Applied Biosystems, USA). The amplifications were performed in a total volume of $10 \mu \mathrm{L}$ and included $5 \mu \mathrm{L}$ of 2 X SYBR Green MasterMix reagent (Thermo Fisher Scientific, Rockford, IL, USA), $1 \mu \mathrm{L}$ of cDNA and $0.2 \mu \mathrm{L}$ of each primer $(10 \mu \mathrm{M})$. The thermal cycling profile consisted of an initial denaturation at $95^{\circ} \mathrm{C}$ for 5 min followed by 40 cycles of denaturation at $95^{\circ} \mathrm{C}$ for $15 \mathrm{~s}$ and annealing/extension at $60^{\circ} \mathrm{C}$ for $45 \mathrm{~s}$. An additional temperature-ramping step from 95 to $65^{\circ} \mathrm{C}$ was performed to enervate the melting curve. All samples were examined in triplicates of two biology replicates and accompanied with negative controls. The $\beta$-actin was used as the internal control and the relative expression was calculated by the $2^{-\Delta \Delta C t}$ method [39].

\subsection{Statistical Analysis}

The statistical analysis of miR-34a in fish livers by qRT-PCR was analyzed using student's $t$-test in Graphad prism 6.0 (Graphpad Software, San Diego, CA, USA). $p<0.05$ was set as the criteria for statistically significant.

Supplementary Materials: Supplementary materials can be found at http:/ /www.mdpi.com/1422-0067/19/8/ 2417/s1.

Author Contributions: L.-H.M. and X.-P.G. designed and supervised the study. W.-J.P., Y.L., X.H. performed research. Q.-L.Z., B.L., M.-C.R. and L.-K.P. assisted sampling. L.-H.M., W.-J.P. and Y.L. performed biochemical index test and qRT-PCR test. L.-H.M. analyzed transcriptome data and prepared Tables and Figures. L.-H.M. wrote the paper; which was read, reviewed and approved by all authors.

Funding: This research was funded by the National Natural Science Foundation of China grant numbers 31602177, Central Public-interest Scientific Institution Basal Research Fund, Freshwater Fisheries Research Center, CAFS (NO. 2017JBFM05) and the Earmarked Fund for China Agriculture Research System grant number CARS-45.

Acknowledgments: The authors gratefully acknowledge the postgraduate students of Fish Disease and Nutrition Department, FFRC, CAFS, Wuxi City, PR China for their help during the experiment.

Conflicts of Interest: The authors declare no conflict of interest.

\section{Abbreviations}

FAO Food and Agriculture Organization

DEM Differentially expressed miRNA

T2D Type 2 diabetes

NAFLD Non-alcoholic fatty liver disease

ACSL1 Acyl-CoA synthetase long-chain family member 1

FOXO1 Forkhead box protein O1

PPARs Peroxisome proliferator-activated receptors

PGC-1 $\alpha \quad$ Peroxisome proliferator-activated receptor $\gamma$ coactivator $1-\alpha$

COG Cluster of Orthologous Groups of protein 


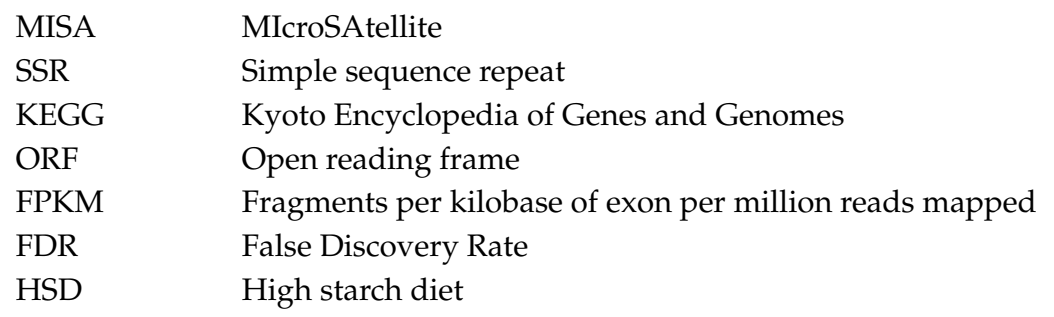

\section{References}

1. Englyst, H.N.; Hudson, G.J. The classification and measurement of dietary carbohydrates. Food Chem. 1996, 57, 15-21. [CrossRef]

2. Asp, N.G. Dietary carbohydrates: Classification by chemistry and physiology. Food Chem. 1996, 57, 9-14. [CrossRef]

3. Hemre, G.I.; Mommsen, T.P.; Krogdahl, A. Carbohydrates in fish nutrition: Effects on growth, glucose metabolism and hepatic enzymes. Aquac. Nutr. 2015, 8, 175-194. [CrossRef]

4. Li, X.F.; Wang, Y.; Liu, W.B.; Jiang, G.Z.; Zhu, J. Effects of dietary carbohydrate/lipid ratios on growth performance, body composition and glucose metabolism of fingerling blunt snout bream Megalobrama amblycephala. Aquac. Nutr. 2013, 19, 701-708. [CrossRef]

5. Hung, L.T.; Lazard, J.; Mariojouls, C.; Moreau, Y. Comparison of starch utilization in fingerlings of two Asian catfishes from the Mekong River (Pangasius bocourti Sauvage, 1880, Pangasius Hypophthalmus Sauvage, 1878). Aquac. Nutr. 2015, 9, 215-222. [CrossRef]

6. Watanabe, T. Strategies for further development of aquatic feeds. Fish. Sci. 2002, 68, 242-252. [CrossRef]

7. Yi, S.; Gao, Z.X.; Zhao, H.; Zeng, C.; Luo, W.; Chen, B.; Wang, W.M. Identification and characterization of microRNAs involved in growth of blunt snout bream (Megalobrama amblycephala) by Solexa sequencing. BMC Genom. 2013, 14, 754. [CrossRef] [PubMed]

8. Li, Z.; Xu, L.; Liu, W.; Liu, Y.; Ringø, E.; Du, Z.; Zhou, Z. Protein replacement in practical diets altered gut allochthonous bacteria of cultured cyprinid species with different food habits. Aquac. Int. 2015, 23, 913-928. [CrossRef]

9. Miao, L.H.; Lin, Y.; Pan, W.J.; Huang, X.; Ge, X.P.; Ren, M.C.; Zhou, Q.L.; Liu, B. Identification of differentially expressed microRNAs associate with glucose metabolism in different organs of blunt snout bream (Megalobrama amblycephala). Int. J. Mol. Sci. 2017, 18, 1161. [CrossRef] [PubMed]

10. Zhou, C.; Liu, B.; Xie, J.; Ge, X. Effect of High Dietary Carbohydrate on Growth, Serum Physiological Response, and Hepatic Heat Shock Protein 70 Expression of Wuchang Bream (Megalobrama amblycephala) at Two Temperatures. Turk. J. Fish. Aquat. Sci. 2013, 13, 211-220. [CrossRef]

11. Zhou, C.; Liu, B.; Ge, X.; Xie, J.; Xu, P. Effect of dietary carbohydrate on the growth performance, immune response, hepatic antioxidant abilities and heat shock protein 70 expression of Wuchang bream, Megalobrama amblycephala. J. Appl. Ichthyol. 2013, 29, 1348-1356. [CrossRef]

12. Zhou, C.; Ge, X.P.; Liu, B.; Xie, J.; Miao, L.H. Effect of Dietary Carbohydrate Level on Growth Performance, Blood Chemistry, Hepatic Enzyme Activity, and Growth Hormone Gene Expression in Wuchang Bream (Megalobrama amblycephala). Isr. J. Aquac.-Bamidgeh 2013, 65, 1-8.

13. Ghawanmeh, T.; Thunberg, U.; Castro, J.; Murray, F.; Laytragoon-Lewin, N. miR-34a expression, cell cycle arrest and cell death of malignant mesothelioma cells upon treatment with radiation, docetaxel or combination treatment. Oncology 2011, 81, 330-335. [CrossRef] [PubMed]

14. Li, X.J.; Ren, Z.J.; Tang, J.H. MicroRNA-34a: A potential therapeutic target in human cancer. Cell Death Dis. 2014, 5, e1327. [CrossRef] [PubMed]

15. Lovis, P.; Roggli, E.; Laybutt, D.R.; Gattesco, S.; Yang, J.Y.; Widmann, C.; Abderrahmani, A.; Regazzi, R. Alterations in microRNA expression contribute to fatty acid-induced pancreatic $\beta$-cell dysfunction. Diabetes 2008, 57, 2728-2736. [CrossRef] [PubMed]

16. Roggli, E.; Britan, A.; Gattesco, S.; Lin-Marq, N.; Abderrahmani, A.; Meda, P.; Regazzi, R. Involvement of microRNAs in the cytotoxic effects exerted by proinflammatory cytokines on pancreatic $\beta$-cells. Diabetes 2010, 59, 978-986. [CrossRef] [PubMed] 
17. Li, S.; Chen, X.; Zhang, H.; Liang, X.; Xiang, Y.; Yu, C.; Zen, K.; Li, Y.; Zhang, C.Y. Differential expression of microRNAs in mouse liver under aberrant energy metabolic status. J. Lipid Res. 2009, 50, 1756-1765. [CrossRef] [PubMed]

18. Trajkovski, M.; Hausser, J.; Soutschek, J.; Bhat, B.; Akin, A.; Zavolan, M.; Heim, M.H.; Stoffel, M. MicroRNAs 103 and 107 regulate insulin sensitivity. Nature 2011, 474, 649-653. [CrossRef] [PubMed]

19. Xie, H.; Bing, L.; Lodish, H.F. MicroRNAs induced during adipogenesis that accelerate fat cell development are downregulated in obesity. Diabetes 2009, 58, 1050-1057. [CrossRef] [PubMed]

20. Cermelli, S.; Ruggieri, A.; Marrero, J.A.; Ioannou, G.N.; Beretta, L. Circulating microRNAs in patients with chronic hepatitis C and non-alcoholic fatty liver disease. PLoS ONE 2011, 6, e23937. [CrossRef] [PubMed]

21. Kong, L.; Zhu, J.; Han, W.; Jiang, X.; Xu, M.; Zhao, Y.; Dong, Q.; Pang, Z.; Guan, Q.; Gao, L.; et al. Significance of serum microRNAs in pre-diabetes and newly diagnosed type 2diabetes: A clinical study. Acta Diabetol. 2011, 48, 61-69. [CrossRef] [PubMed]

22. Yamakuchi, M.; Ferlito, M.; Lowenstein, C.J. miR-34a repression of sirt1 regulates apoptosis. Proc. Natl. Acad. Sci. USA 2008, 105, 13421-13426. [CrossRef] [PubMed]

23. Li, W.Q.; Chen, C.; Xu, M.D.; Guo, J.; Li, Y.M.; Xia, Q.M.; Liu, H.M.; He, J.; Yu, H.Y.; Zhu, L. The rno-miR-34 family is upregulated and targets ACSL1 in dimethylnitrosamine-induced hepatic fibrosis in rats. FEBS J. 2011, 278, 1522-1532. [CrossRef] [PubMed]

24. Rottiers, V.; Näär, A.M. MicroRNAs in metabolism and metabolic disorders. Nat. Rev. Mol. Cell Biol. 2012, 13, 239-250. [CrossRef] [PubMed]

25. Zhou, J.; Meng, Y.; Tian, S.; Chen, J.; Liu, M.; Zhuo, M.; Zhang, Y.; Du, H.; Wang, X. Comparative microRNA expression profiles of cynomolgus monkeys, rat, and human reveal that miR-182 is involved in T2D pathogenic processes. J. Diabetes Res. 2014, 2014, 760397. [CrossRef] [PubMed]

26. Tryndyak, V.P.; Ross, S.A.; Beland, F.A.; Pogribny, I.P. Down-regulation of the microRNAs miR-34a, miR-127, and miR-200b in rat liver during hepatocarcinogenesis induced by a methyl-deficient diet. Mol. Carcinog. 2009, 48, 479-487. [CrossRef] [PubMed]

27. Castro, R.E.; Ferreira, D.M.; Afonso, M.B.; Borralho, P.M.; Machado, M.V.; Cortez-Pinto, H.; Rodrigues, C.M. $\mathrm{miR}-34 \mathrm{a} / \mathrm{SIRT} 1 / \mathrm{p} 53$ is suppressed by ursodeoxycholic acid in the rat liver and activated by disease severity in human non-alcoholic fatty liver disease. J. Hepatol. 2013, 58, 119-125. [CrossRef] [PubMed]

28. Jia, L.; Lam, M. Registered report: The microRNA miR-34a inhibits prostate cancer stem cells and metastasis by directly repressing CD44. J. Urol. 2011, 186, 211-215.

29. Gurzov, E.N.; Stanley, W.J.; Pappas, E.G.; Thomas, H.E.; Gough, D.J. The JAK-STAT pathway in obesity and diabetes. FEBS J. 2016, 283, 3002-3015. [CrossRef] [PubMed]

30. Farooqi, I.S.; O’Rahilly, S. 20 years of leptin:human disorders of leptin action. J. Endocrinol. 2014, 223, T63-T70. [CrossRef] [PubMed]

31. Hamilton-Williams, E.E.; Palmer, S.E.; Charlton, B.; Slattery, R.M. Beta cell MHC class I is a late requirement for diabetes. Proc. Natl. Acad. Sci. USA 2003, 100, 6688-6693. [CrossRef] [PubMed]

32. Habte-Tsion, H.M.; Ren, M.; Liu, B.; Xie, J.; Ge, X.; Chen, R.; Zhou, Q.; Pan, L. Threonine affects digestion capacity and hepatopancreatic gene expression of juvenile blunt snout bream (Megalobrama amblycephala). Br. J. Nutr. 2015, 114, 533-543. [CrossRef] [PubMed]

33. Lee, J.; Kemper, J.K. Controlling SIRT1 expression by microRNAs in health and metabolic disease. Aging 2010, 2, 527-534. [CrossRef] [PubMed]

34. Kemper, J.K.; Xiao, Z.; Ponugoti, B.; Miao, J.; Fang, S.; Kanamaluru, D.; Tsang, S.; Wu, S.Y.; Chiang, C.M.; Veenstra, T.D. FXR acetylation is normally dynamically regulated by p300 and SIRT1 but constitutively elevated in metabolic disease states. Cell Metab. 2009, 10, 392-404. [CrossRef] [PubMed]

35. Li, X.; Zhang, S.; Blander, G.; Tse, J.G.; Krieger, M.; Guarente, L. SIRT1 deacetylates and positively regulates the nuclear receptor LXR. Mol. Cell 2007, 28, 91-106. [CrossRef] [PubMed]

36. Motta, M.C.; Divecha, N.; Lemieux, M.; Kamel, C.; Chen, D.; Gu, W.; Bultsma, Y.; McBurney, M.; Guarente, L. Mammalian SIRT1 represses forkhead transcription factors. Cell 2004, 116, 551-563. [CrossRef]

37. Ponugoti, B.; Kim, D.H.; Xiao, Z.; Smith, Z.; Miao, J.; Zang, M.; Wu, S.Y.; Chiang, C.M.; Veenstra, T.D.; Kemper, J.K. SIRT1 deacetylates and inhibits SREBP-1C activity in regulation of hepatic lipid metabolism. J. Biol. Chem. 2010, 285, 33959-33970. [CrossRef] [PubMed] 
38. Purushotham, A.; Schug, T.T.; Xu, Q.; Surapureddi, S.; Guo, X.; Li, X. Hepatocyte-specific deletion of SIRT1 alters fatty acid metabolism and results in hepatic steatosis and inflammation. Cell Metab. 2009, 9, 327-338. [CrossRef] [PubMed]

39. Vaziri, H.; Dessain, S.K.; Ng Eaton, E.; Imai, S.I.; Frye, R.A.; Pandita, T.K.; Guarente, L.; Weinberg, R.A. hSIR2(SIRT1) functions as an NAD-dependent p53 deacetylase. Cell 2001, 107, 149-159. [CrossRef]

40. Walker, A.K.; Yang, F.; Jiang, K.; Ji, J.Y.; Watts, J.L.; Purushotham, A.; Boss, O.; Hirsch, M.L.; Ribich, S.; Smith, J.J.; et al. Conserved role of SIRT1 orthologs in fasting-dependent inhibition of the lipid/cholesterol regulator SREBP. Genes Dev. 2010, 24, 1403-1417. [CrossRef] [PubMed]

41. Fan, Y.; Hoberg, J.E.; Ramsey, C.S.; Keller, M.D.; Jones, D.R.; Frye, R.A.; Mayo, M.W. Modulation of NF-кB-dependent transcription and cell survival by the SIRT1 deacetylase. EMBO J. 2004, 23, 2369-2380.

42. And, J.B.; Moller, D.E. The mechanisms of action of PPARs. Annu. Rev. Med. 2002, 53, 409-435.

43. Feige, J.N.; Gelman, L.; Michalik, L.; Desvergne, B.; Wahli, W. From molecular action to physiological outputs: Peroxisome proliferator-activated receptors are nuclear receptors at the crossroads of key cellular functions. Prog. Lipid Res. 2002, 45, 120-159. [CrossRef] [PubMed]

44. Sanderson, L.M.; Boekschoten, M.V.; Desvergne, B.; Müller, M.; Kersten, S. Transcriptional profiling reveals divergent roles of PPAR $\alpha$ and PPAR $\beta / \delta$ in regulation of gene expression in mouse liver. Physiol. Genom. 2010, 41, 42-52. [CrossRef] [PubMed]

45. Miao, L.H.; Pan, W.J.; Ge, X.P.; Liu, B.; Ren, M.C.; Zhou, Q.L. Bioinformatic prediction and analysis of glucolipid metabolic regulation by miR-34a in Megalobrama amblycephala. Genes Genom. 2017, 39, 1407-1417. [CrossRef]

46. Chen, K.; Zhao, L.; He, H.; Wan, X.; Wang, F.; Mo, Z. Silibinin protects $\beta$ cells from glucotoxicity through regulation of the Insig-1/SREBP-1c pathway. Int. J. Mol. Med. 2014, 34, 1073-1080. [CrossRef] [PubMed]

47. Zhan, T.; Poppelreuther, M.; Ehehalt, R.; Füllekrug, J. Overexpressed FATP1, ACSVL4/FATP4 and ACSL1 increase the cellular fatty acid uptake of 3T3-L1 adipocytes but are localized on intracellular membranes. PLoS ONE 2012, 7, e45087. [CrossRef] [PubMed]

48. Phosat, C.; Panprathip, P.; Chumpathat, N.; Prangthip, P.; Chantratita, N.; Soonthornworasiri, N.; Kwanbunjan, K. Elevated, C-reactive protein, interleukin 6, tumor necrosis factor $\alpha$ and glycemic load associated with type 2 diabetes mellitus in rural Thais: A cross-sectional study. BMC Endocr. Disord. 2017, 17, 44. [CrossRef] [PubMed]

49. Long, Y.C.; Zierath, J.R. AMP-activated protein kinase signaling in metabolic regulation. J. Clin. Investig. 2006, 116, 1776-1783. [CrossRef] [PubMed]

50. Saltiel, A.R.; Kahn, C.R. Insulin signaling and the regulation of glucose and lipid metabolism. Nature 2002, 414, 799-806. [CrossRef] [PubMed]

51. Lochhead, P.A.; Salt, I.P.; Walker, K.S.; Hardie, D.G.; Sutherland, C. 5-aminoimidazole-4-carboxamide riboside mimics the effects of insulin on the expression of the 2 key gluconeogenic genes PEPCK and glucose-6-phosphatase. Diabetes 2000, 49, 896-903. [CrossRef] [PubMed]

52. Andreelli, F.; Foretz, M.; Knauf, C.; Cani, P.D.; Perrin, C.; Iglesias, M.A.; Pillot, B.; Bado, A.; Tronche, F.; Mithieux, G.; et al. Liver adenosine monophosphate-activated kinase- $\alpha 2$ catalytic subunit is a key target for the control of hepatic glucose production by adiponectin and leptin but not insulin. Endocrinology 2006, 147, 2432-2441. [CrossRef] [PubMed]

53. Gan, Z.; Burkart-Hartman, E.M.; Han, D.H.; Finck, B.; Leone, T.C.; Smith, E.Y.; Ayala, J.E.; Holloszy, J.; Kelly, D.P. The nuclear receptor PPAR $\beta / \delta$ programs muscle glucose metabolism in cooperation with AMPK and MEF2. Genes Dev. 2011, 25, 2619-2630. [CrossRef] [PubMed]

54. Ren, M.; Liao, Y.; Xie, J.; Liu, B.; Zhou, Q.; Ge, X.; Cui, H.; Pan, L.; Chen, R. Dietary arginine requirement of juvenile blunt snout bream, Megalobrama amblycephala. Aquaculture 2013, 414, 229-234. [CrossRef]

55. Grabherr, M.G.; Haas, B.J.; Yassour, M.; Levin, J.Z.; Thompson, D.A.; Amit, I.; Adiconis, X.; Fan, L.; Raychowdhury, R.; Zeng, Q.; et al. Full-length transcriptome assembly from RNA-Seq data without a reference genome. Nat. Biotechnol. 2011, 29, 644-652. [CrossRef] [PubMed]

56. Li, W.; Godzik, A. Cd-hit: A fast program for clustering and comparing large sets of protein or nucleotide sequences. Bioinformatics 2006, 22, 1658-1659. [CrossRef] [PubMed]

57. Deng, Y.; Li, J.; Wu, S.; Zhu, Y.; Chen, Y.; He, F. Integrated NR database in protein annotation system and its localization. Comput. Eng. 2006, 32, 71-74. 
58. Apweiler, R.; Bairoch, A.; Wu, C.H.; Barker, W.C.; Boeckmann, B.; Ferro, S.; Gasteiger, E.; Huang, H.; Lopez, R.; Magrane, M.; et al. UniProt: The Universal Protein knowledgebase. Nucleic Acids Res. 2004, 32, D115-D119. [CrossRef] [PubMed]

59. Tatusov, R.L.; Galperin, M.Y.; Natale, D.A.; Koonin, E.V. The COG database: A tool for genome-scale analysis of protein functions and evolution. Nucleic Acids Res. 2000, 28, 33-36. [CrossRef] [PubMed]

60. Finn, R.D.; Bateman, A.; Clements, J.; Coggill, P.; Eberhardt, R.Y.; Eddy, S.R.; Heger, A.; Hetherington, K.; Holm, L.; Mistry, J.; et al. Pfam: The protein families database. Nucleic Acids Res. 2014, 42, 222-230. [CrossRef] [PubMed]

61. Altschul, S.F.; Madden, T.L.; Schäffer, A.A.; Zhang, J.; Zhang, Z.; Miller, W.; Lipman, D.J. Gapped BLAST and PSI-BLAST: A new generation of protein database search programs. Nucleic Acids Res. 1997, 25, 3389-3402. [CrossRef] [PubMed]

62. Langmead, B.; Trapnell, C.; Pop, M.; Salzberg, S.L. Ultrafast and memory-efficient alignment of short DNA sequences to the human genome. Genome Biol. 2009, 10, R25. [CrossRef] [PubMed]

63. Li, B.; Dcwcy, C.N. RSEM: Accurate transcript quantification from RNA-Seq data with or without a reference genome. BMC Bioinform. 2011, 12, 323. [CrossRef] [PubMed]

64. Robinson, M.D.; Mccarthy, D.J.; Smyth, G.K. edgeR: A Bioconductor package for differential expression analysis of digital gene expression data. Bioinformatics 2010, 26, 139-140. [CrossRef] [PubMed]

65. Boyle, E.I.; Weng, S.; Gollub, J.; Jin, H.; Botstein, D.; Cherry, J.M.; Sherlock, G. GO::TermFinder-Open source software for accessing Gene Ontology information and finding significantly enriched Gene Ontology terms associated with a list of genes. Bioinformatics 2004, 20, 3710-3715. [CrossRef] [PubMed]

66. Xie, C.; Mao, X.; Huang, J.; Ding, Y.; Wu, J.; Dong, S.; Kong, L.; Gao, G.; Li, C.Y.; Wei, L. KOBAS 2.0: A web server for annotation and identification of enriched pathways and diseases. Nucleic Acids Res. 2011, 39, W316-W322. [CrossRef] [PubMed]

(C) 2018 by the authors. Licensee MDPI, Basel, Switzerland. This article is an open access article distributed under the terms and conditions of the Creative Commons Attribution (CC BY) license (http://creativecommons.org/licenses/by/4.0/). 